Gynecologic and

Obstetric Investigation
Gynecol Obstet Invest 2018;83:521-532

DOI: $10.1159 / 000488241$
Received: January 4, 2018

Accepted after revision: March 7, 2018

Published online: April 12, 2018

\title{
What Is the Role of Barbed Suture in Laparoscopic Myomectomy? A Meta-Analysis and Pregnancy Outcome Evaluation
}

\author{
Barbara Gardella $^{\mathrm{a}}$ Mattia Dominoni ${ }^{\mathrm{a}} \quad$ Anna Daniela lacobone $^{\mathrm{b}}$ \\ Annalisa De Silvestric Carmine Tinellic Stefano Bogliolo, ${ }^{a}$ d Arsenio Spinillo ${ }^{a}$ \\ ${ }^{a}$ Department of Obstetrics and Gynaecology, University of Pavia, Fondazione IRCCS Policlinico, Pavia, Italy; \\ ${ }^{b}$ Preventive Gynecology Unit, European Institute of Oncology, Milan, Italy; ' Service of Biometry and Statistics, IRCCS \\ Fondazione Policlinico San Matteo, Pavia, Italy; ${ }^{d}$ Division of Gynecologic Oncology, European Institute of Oncology, \\ Milan, Italy
}

\section{Keywords}

Barbed suture · Laparoscopy · Myomectomy ·

Meta-analysis · Pregnancy

\begin{abstract}
Background: This work analyzes the feasibility and effectiveness of barbed suture during laparoscopic myomectomy. Methods: Eight works have been carefully examined for the meta-analysis from all papers published online until November 2017. Results: Barbed suture proved to be superior to traditional suture technique in blood loss in laparoscopic myomectomy (Standardized Mean Difference [SMD] -0.650, $95 \% \mathrm{Cl}-1.420$ to $-0.119, p=0.098$, test for heterogenity $p<$ $\left.0.0001, \mathrm{I}^{2}=95.54 \%\right), \mathrm{Hb}$ drop (SMD $-1.452,95 \% \mathrm{Cl}-3.590$ to $0.687, p=0.183$, test for heterogenity $\left.p<0.0001, I^{2}=99.08 \%\right)$, suturing difficulty (SMD $-0.638,95 \% \mathrm{Cl}-0.935$ to $-0.342, p \leq$ 0.001 , test for heterogenity $p=0.25, \mathrm{I}^{2}=27.84 \%$ ), suturing time (SMD $-1.197,95 \% \mathrm{Cl}-1.848$ to $-0.549, p \leq 0.001$, test for heterogenity $p=0.0001, \mathrm{I}^{2}=83.30 \%$ ) and total operative time (SMD $-0.687,95 \% \mathrm{Cl}-0.804$ to $-0.569, p \leq 0.001$, test for heterogenity $p=0.292, I^{2}=17.44 \%$ ). Barbed suture demonstrated to be better in comparison with the control group
\end{abstract}

\section{KARGER}

(c) 2018 S. Karger AG, Basel

E-Mail karger@karger.com

www.karger.com/goi even with regard to the length of hospitalization (SMD $-0.278,95 \% \mathrm{Cl}-0.543$ to $0.012, p=0.040$, test for heterogenity $p=0.025, I^{2}=61.85 \%$ ), and to perioperative complications (SMD 0.708, 95\% Cl 0.503-0.996, $p=0.048$, test for heterogenity $\left.p=0.79, \mathrm{I}^{2}=0 \%\right)$. Conclusion: Barbed suture significantly facilitates laparoscopic myomectomy by reducing the total operative/suturing time, estimated blood loss/Hb drop, and reduction of perioperative complications.

(c) 2018 S. Karger AG, Basel

\section{Introduction}

Uterine myoma is the most common benign tumor of the female genital tract. Usually, there are no symptoms associated to myoma. However, myoma can often cause pelvic pain, metrorrhagia, and abnormal uterine bleeding in $25 \%$ of women [1-3]. Uterine myomas may also be related to reproductive dysfunctions [3]. The management of myomas concerns the following aspects: number, size, location, surgical experience, age of patient, and the desire of future pregnancy. There are several surgical procedures to perform the myomectomy: laparoscopy, hyster- 
oscopy, robotic-assisted laparoscopy, and laparotomy [4]. Hysteroscopic miomectomy is an effective technique for the management of submucous myomas; in particular, hysteroscopic morcellation, by reducing the total operative time, operative complications, postoperative adhesions, and increasing patient's satisfaction [5]. Laparotomic myomectomy should be considered the traditional surgical treatment in patients of the childbearing age [6]. Nevertheless, laparoscopic management could be a valid alternative to laparotomic approach, with substantial advantages, such as reduction of postoperative pain and hospital stay, drop of blood loss and better cosmetic results of surgical scars [7-12]. Also, transvaginal hydrolaparoscopy has proved itself to be a procedure that reduces the postoperative adhesions and fibrous connection adhesion; in fact, it is less traumatic than traditional laparoscopy. This approach can be useful in the treatment of myomas of uterine posterior wall $[13,14]$.

Speaking of uterine myomas, it is already known that the choice of the surgical procedure mainly depends on surgeon's experience and abilities. But, according to the current scenario, the most important factors influencing surgical outcome of myomectomy are the suture of the uterine wall wound and the risk of hemorrhage. Indeed, the suture of myometrial breaches requires careful hemostasis, with the slightest involvement of surrounding tissues, an optimal distribution of forces and tensions along the suture line and decreased inflammatory reaction [15]. In order to reduce bleeding during myoma enucleation, different procedures have been introduced, including uterine artery ligation, intramyometrial vasopressin injection, oxytocin perfusion, and preoperative treatment with gonadotropin-releasing hormone analogue [16-18].

Uterine muscular wall defects are usually sutured by absorbable filaments, but great surgical abilities and experience are required to perform intra-corporeal knots during laparoscopic procedures. Nowadays, the introduction of absorbable barbed suture in laparoscopic gynecological surgery has entailed good results and several surgical facilitations because there is no need of intracorporeal knots to ensure good control of tissue bleeding [19-23]. Indeed, the presence of barbs leads to the cohesion of filament to tissues, and intra-corporeal knots are not required. This suture is simple and really useful in laparoscopic surgery. Since commercialization started in 2007, 2 different types of barbed sutures are available: bidirectional and unidirectional sutures. The bidirectional filament consists of 2 needles. The suture starts in the middle of the breach and continues in one direction with a needle and in the opposite direction with the other needle. Conversely, unidirec- tional filament has only one needle at an extremity and a loop at the opposite extremity. Hence, a continuous suture can be performed. Moreover, barbed filaments include absorbable and nonabsorbable monofilaments. Recently, a third type of barbed filament, characterized by barbs distributed in a spiral way, has been introduced in routine laparoscopic surgery [15, 24-27].

The aim of this work was to perform a literature review and meta-analysis, comparing the feasibility and effectiveness of classic intra-corporeal knots suture and barbed absorbable suture during laparoscopic myomectomy.

\section{Material and Methods}

In order to realize a review of literature and subsequent metaanalysis, the most important medical databases, including PubMed, Cochrane Database of Systematic Reviews, EMBASE, and Web of Science, were consulted. Different combinations of the following key words were employed in our search strategy: "myomectomy barbed suture," "barbed suture laparoscopy gynecology," "laparoscopic myomectomy barbed suture." For our analysis, all papers published online from 2007 until November 2017, including reports, case series, and retrospective or prospective trials, were considered. Papers have been included in the analysis if the following criteria were met: (i) the myomectomy was performed through laparoscopic approach, (ii) conventional filaments or barbed absorbable sutures, including both bidirectional and unidirectional filaments, were employed. Case reports were considered only for literature review, but they have been excluded from meta-analysis. Exclusion criteria were as follows: (i) works regarding robotic-assisted myomectomies; (ii) abstracts of medical conferences, editorials, and preliminary studies with animal models; (iii) previous reviews and/or surgical videos about barbed sutures during myomectomy; (iv) papers written in languages other than English. For current meta-analysis, we chose the following main outcome measures: blood loss at time of surgery, postoperative hemoglobin $\mathrm{Hb})$ drop, length of hospitalization, suturing time, total operative time, evidence of complications, and surgical difficulty. Surgical difficulty related to the suture of uterine wall defect was assessed on a visual analogical scale (VAS) with values from 1 (low difficulty) to 10 (high difficulty) $[6,11,19,28]$.

\section{Statistical Analysis}

Continuous outcomes, such as blood loss, Hb drop, length of hospitalization, surgical difficulty, and suturing time were metaanalyzed as the Standardized Mean Difference (SMD), which is the difference in means of 2 arms, experimental and control group, divided by pooled standard deviation with $95 \%$. Just for the categorical outcome, that is, postoperative evidence of complications, risk difference was calculated. Fixed models were considered if heterogeneity was low $\left(\mathrm{I}^{2}<50 \%\right)$, otherwise random models were preferred. The fixed-effect model considers only within-study variability, whereas the random-effects model considers both within- and between-study variability. In a random-effects model, it is believed that the included studies represent a random sample from a larger population of studies addressing the question of in-
Gardella/Dominoni/Iacobone/ De Silvestri/Tinelli/Bogliolo/Spinillo 
Fig. 1. Flowchart of papers recorded from bibliographic search.

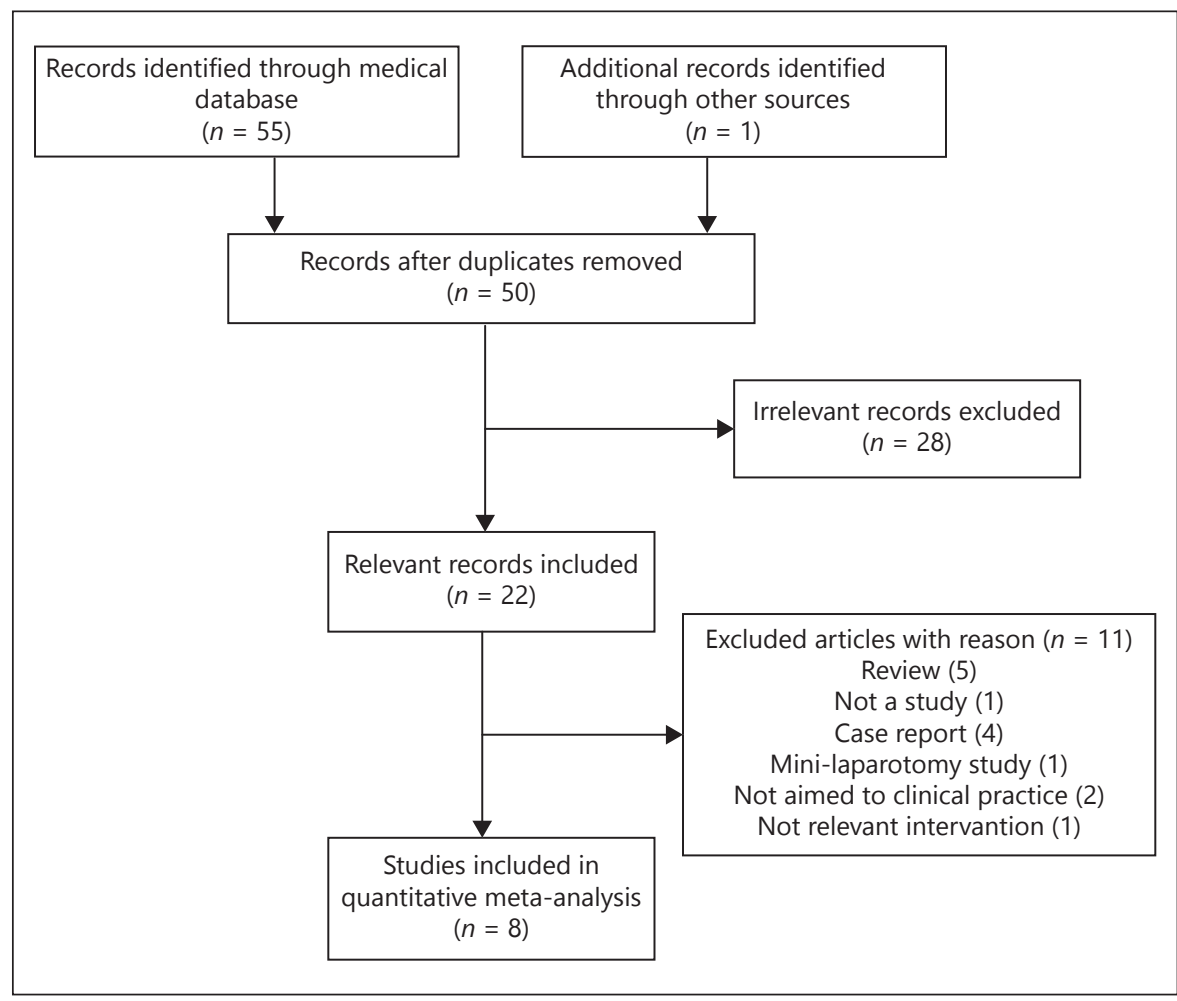

terest. This is why fixed-effect analysis tends to give narrower confidence intervals than a random-effects analysis and the authors choose to be more conservative.

\section{Results}

For our purpose, 55 papers were recorded from bibliographic search. Duplicated papers, presented in more than one database, and irrelevant works were not considered for our analysis. We excluded 38 articles because they discussed the use of barbed suture in vaginal cuff closure after hysterectomy, in uro-gynecological surgery, in obstetrics procedures (i.e., caesarean section), in notgynecological procedures (i.e., prostatectomy), in robotic-assisted laparoscopy, or in reconstructive and plastic surgery. Hence, we retrieved and carefully examined a total of 22 works.

Instead, for meta-analysis, we analyzed only 8 papers, since reports and articles that presented uncompleted data or did not present a control group were excluded. A flowchart (Fig. 1) and Tables 1 and 2 summarize the research investigation, principal demographic, clinical characteristics, and surgical features showed in each paper respectively.

The Use of Barbed Suture in Laparoscopic Myomectomy
In the review of the literature a total of 1,204 women, who underwent laparoscopic myomectomy, were included. In all, 639 women, in which barbed suture was employed for uterine wall defect reparation, were considered cases, while 565 patients, in which traditional sutures were performed, were enrolled as controls.

Patients' age ranged from 33 to 39.3 (mean 36.40 years) and from 32.3 to 39.8 years (mean 35.67 years) in the barbed suture group and in the traditional suture group respectively.

The range of BMI was 22-25.45 (mean $24 \mathrm{~kg} / \mathrm{m}^{2}$ ) and $21.7-27.30 \mathrm{~kg} / \mathrm{m}^{2}$ (mean $24.20 \mathrm{~kg} / \mathrm{m}^{2}$ ) in cases and controls respectively. Myomas showed the following main characteristics in cases and controls respectively: a range of diameter of $3.8-7.7 \mathrm{~cm}$ (mean $5.7 \mathrm{~cm}$ ) and $4.1-7.3 \mathrm{~cm}$ (mean $5.4 \mathrm{~cm}$ ), a range of weight of 208.3353 and $23.7-212.6 \mathrm{~g}$, and a range of number of 1-4 for both groups.

In quantitative meta-analysis 6 papers were considered in order to compare the estimated blood loss during surgical procedure. In laparoscopic myomectomy, barbed suture proved to be superior to traditional suture technique concerning blood loss (SMD - $0.650,95 \%$ CI -1.420 to $-0.119, p=0.098$, test for heterogenity $p<0.0001, \mathrm{I}^{2}=$ 95.5\%; Fig. 2). 


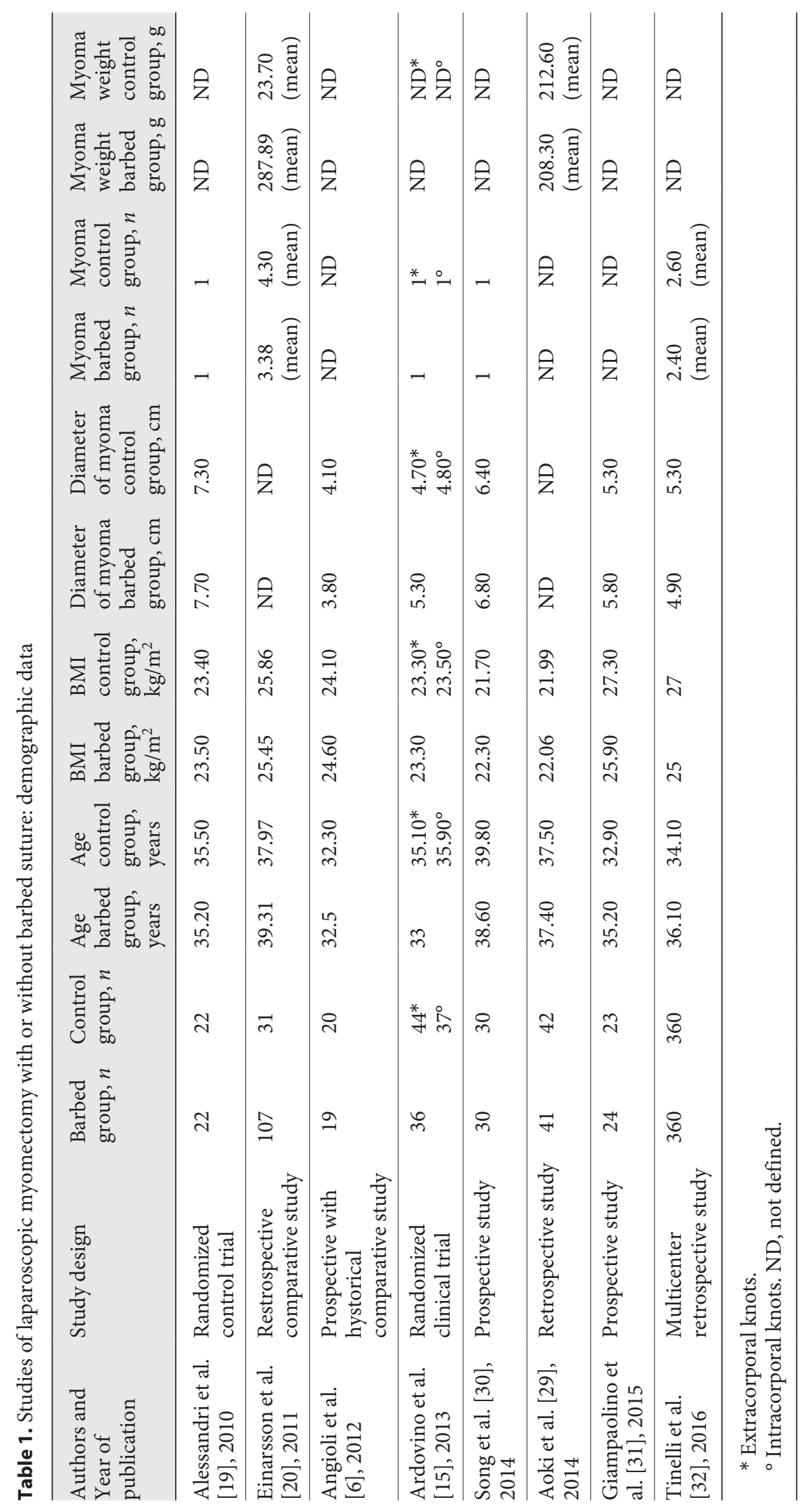




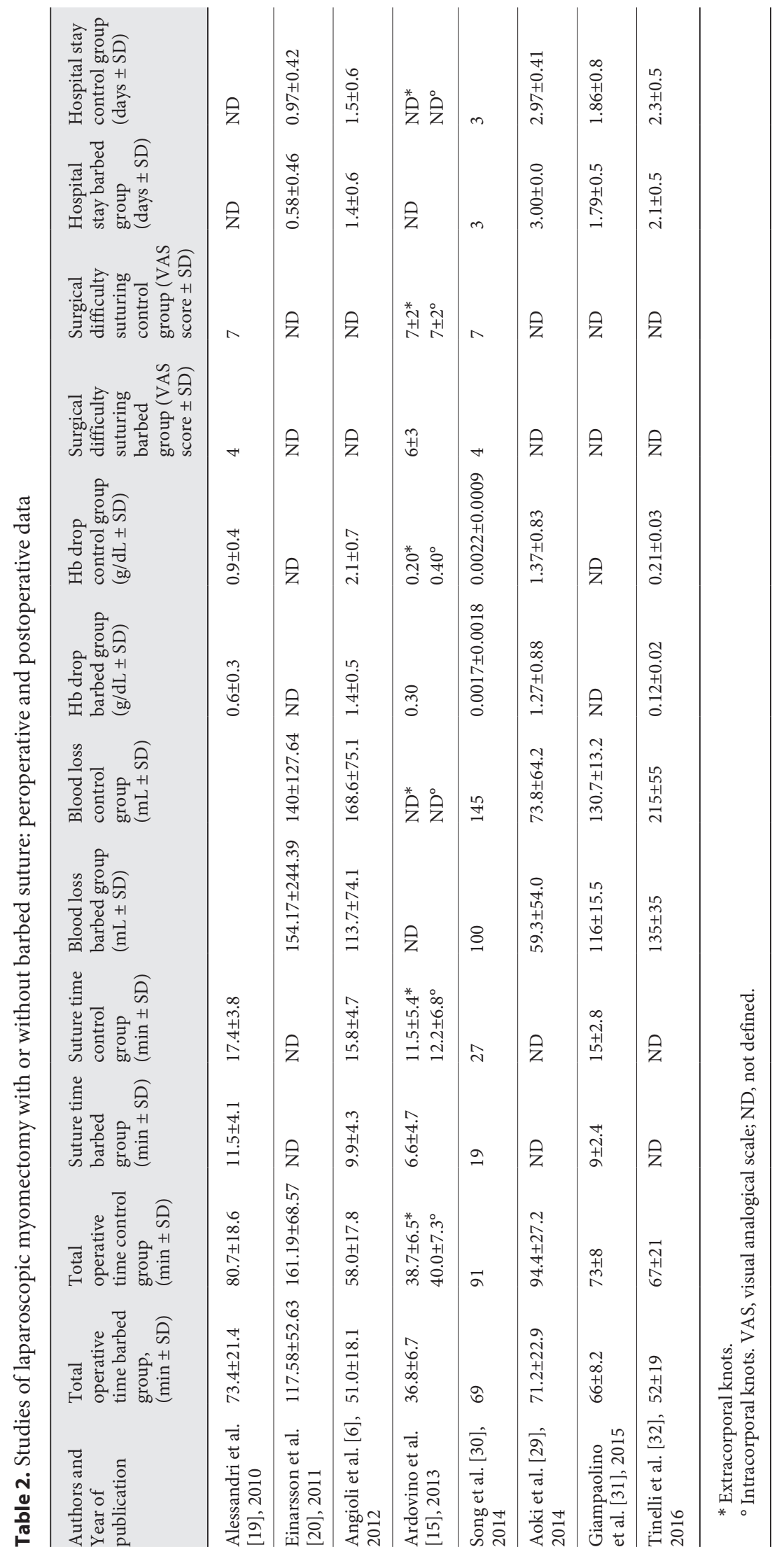




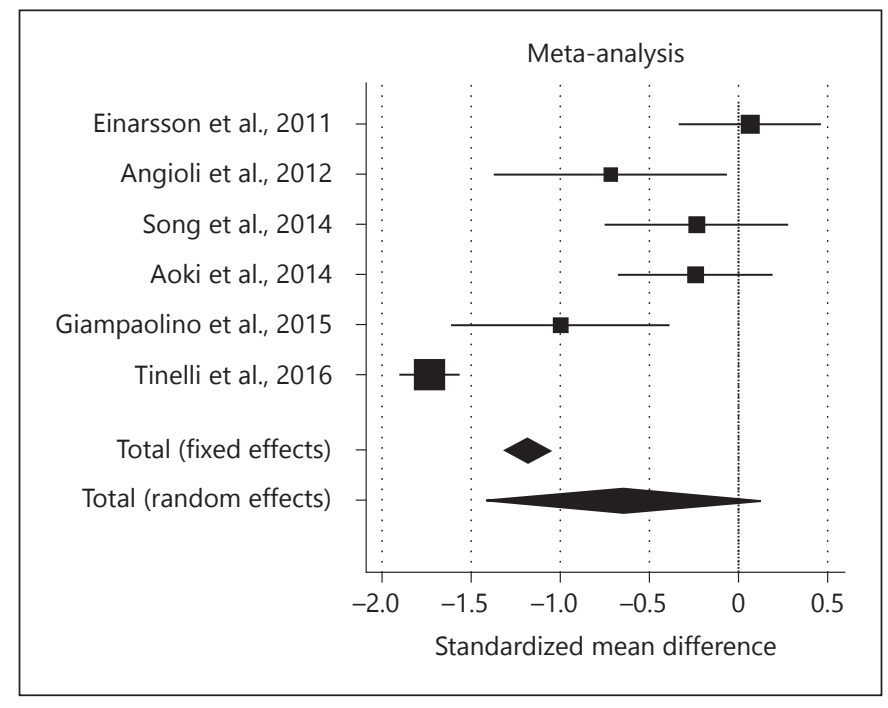

Fig. 2. Forest plot of blood loss during laparoscopic myomectomy.

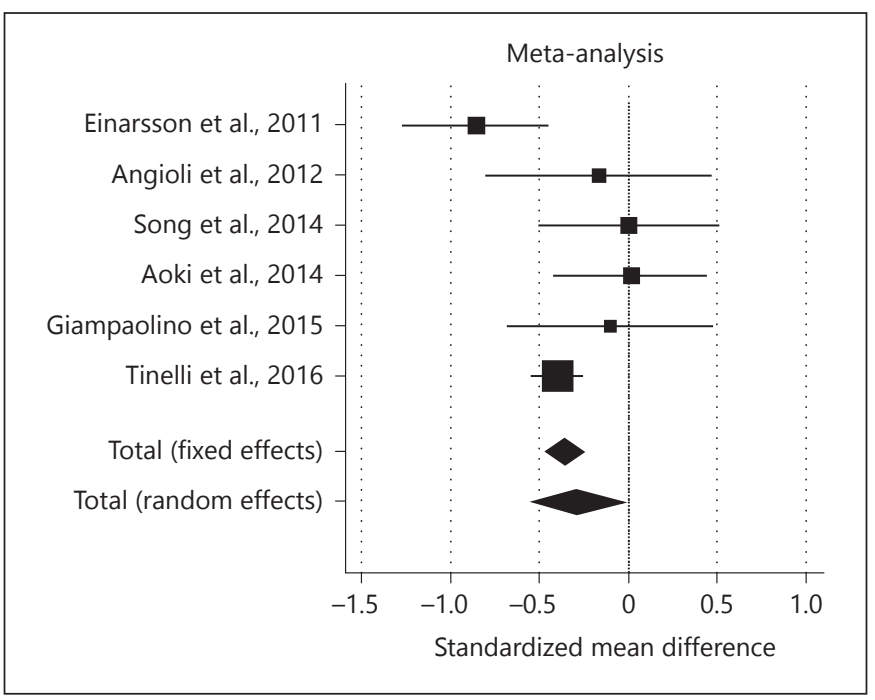

Fig. 4. Forest plot of length of hospitalization after laparoscopic myomectomy and suturing.

Meta-analysis for $\mathrm{Hb}$ drop was based on 5 works. $\mathrm{Hb}$ drop was referred to as the drop between $\mathrm{Hb}$ evaluated the day before the surgery and $\mathrm{Hb}$ estimated $24 \mathrm{~h}$ after surgical procedure. As shown in Figure 3, barbed suture demonstrated to be superior to traditional suture technique also according to $\mathrm{Hb}$ drop (SMD -1.452, 95\% CI -3.590 to $0.687, p=0.183$, test for heterogenity $p<0.0001$, $\mathrm{I}^{2}=99.08 \%$; Fig. 3 ).

Length of hospitalization should be defined as days of recovery from time of surgery. Meta-analysis for this pa-

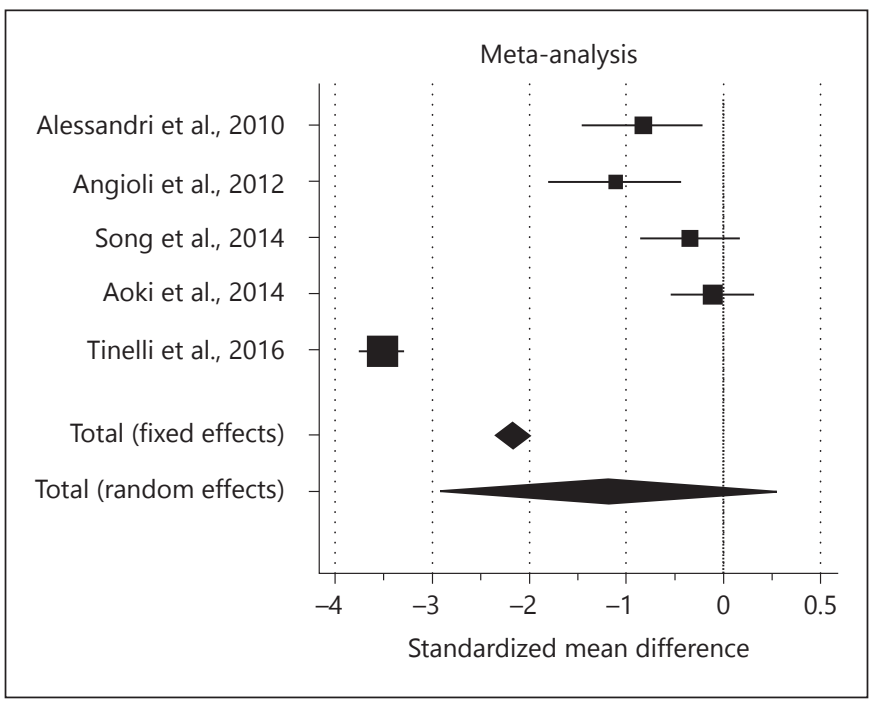

Fig. 3. Forest plot of and hemoglobin drop during laparoscopic myomectomy.

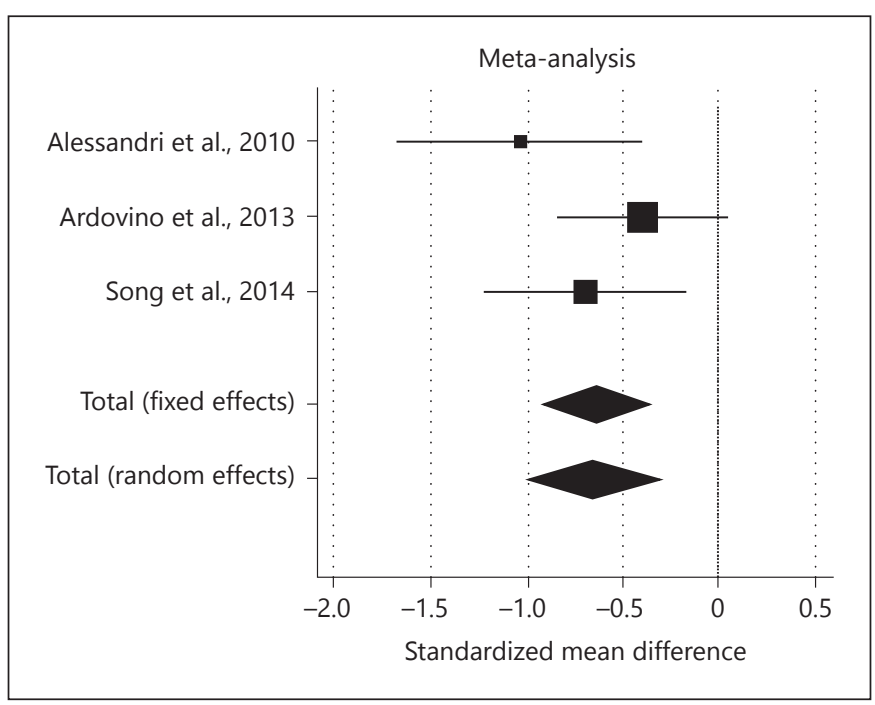

Fig. 5. Forest plot of suturing difficulty during laparoscopic myomectomy with or without barbed suture.

rameter was built on 5 papers. Barbed suture was found to be preferable in comparison with control group (SMD $-0.278,95 \% \mathrm{CI}-0.543$ to $0.012, p=0.040$, test for heterogenity $p=0.025, \mathrm{I}^{2}=61.85 \%$; Fig. 4 ).

Meta-analysis of VAS of suturing difficulty included 3 articles and is reported in Figure 5. In the barbed suture group, VAS was significantly lower than that in the control group (SMD $-0.638,95 \%$ CI -0.935 to $-0.342, p \leq 0.001$, test for heterogenity $p=0.25, \mathrm{I}^{2}=$ $27.84 \%)$. 


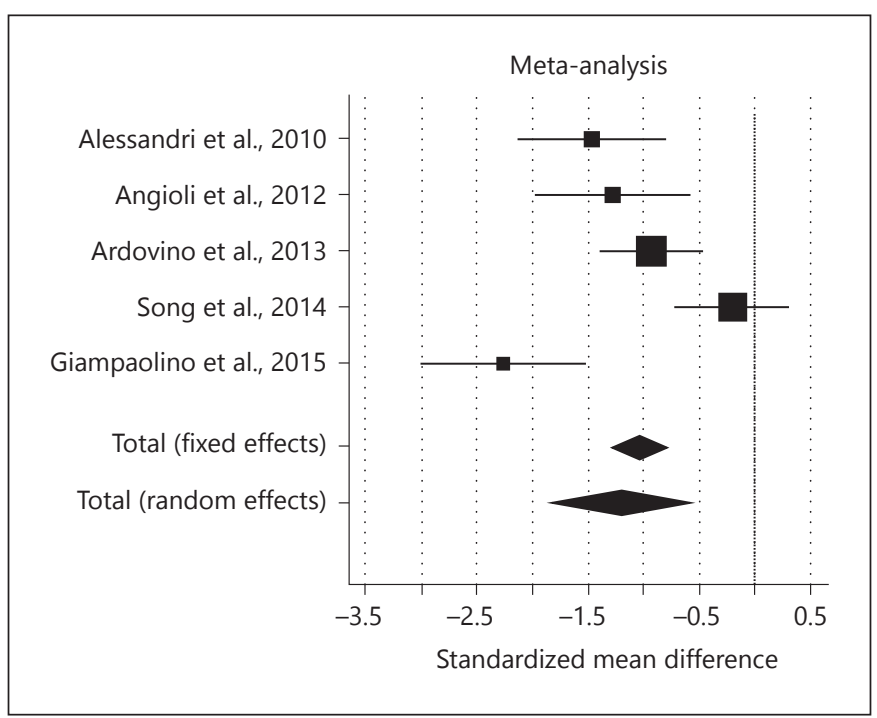

Fig. 6. Forest plot of suturing time during laparoscopic myomectomy with or without barbed suture.

Meta-analysis of suturing time was based on 5 papers. Suturing time was defined as time needed for the suture of uterine wall defect. Also, suturing time was significantly shorter in barbed suture group, as represented in Figure 6 (SMD $-1.201,95 \% \mathrm{CI}-1.848$ to $-0.554, p=<0.001$, test for heterogenity $\left.p=0.0001, \mathrm{I}^{2}=83 \%\right)$.

Time requested to perform the entire myomectomy was defined as the total operative time. Eight works were considered for meta-analysis of this outcome measure. As expected, total operative time was significantly shorter in cases than in controls (SMD $-0.687,95 \%$ CI -0.804 to $-0.569, p \leq 0.001$, test for heterogenity $p=0.292, \mathrm{I}^{2}=$ 17.4\%; Fig. 7).

Meta-analysis of perioperative complications was based on 8 papers. Adverse events in the barbed suture group of patients were significantly lower than those in the control group (SMD 0.708, 95\% CI 0.503-0.996, $p=$ 0.048 , test for heterogenity $p=0.79, \mathrm{I}^{2}=0 \%$; Fig. 8).

In a randomized trial including 44 women treated with unidirectional barbed suture or conventional suture after myomectomy, Alessandri et al. [19] showed that suturing time and the estimated blood loss were lower in the barbed suture group. Even the degree of suturing difficulty, according to different surgeons, was lower in the barbed suture group.

A retrospective randomized trial by Einarsson et al. [20] confirmed that the use of bidirectional barbed suture can reduce suturing time and decrease the length of hospitalization. Conversely, there was no significant differ-

The Use of Barbed Suture in Laparoscopic Myomectomy

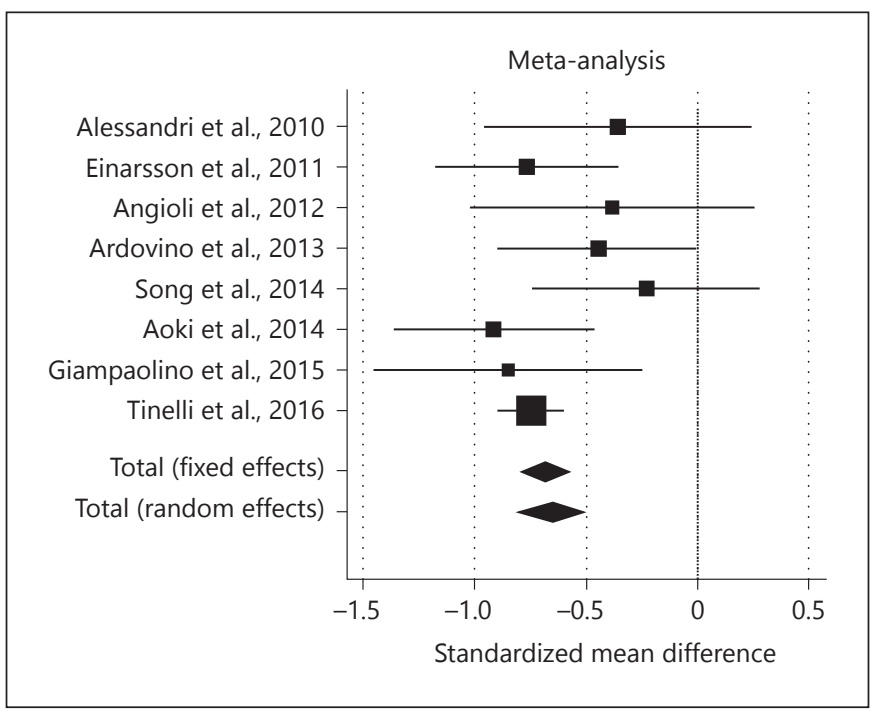

Fig. 7. Forest plot ofd total operative time (b) during laparoscopic myomectomy with or without barbed suture.

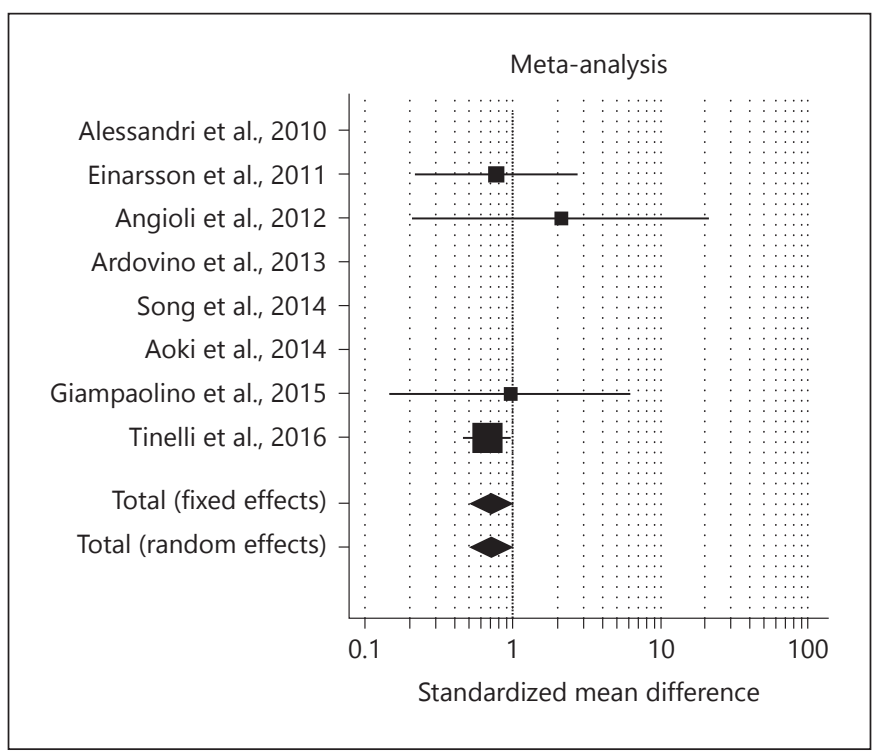

Fig. 8. Forest plot of perioperative complications of laparoscopic myomectomy with or without barbed suture.

ence in the $\mathrm{Hb}$ drop and in the incidence of postoperative complications.

Also, Angioli et al. [6] compared the traditional intracorporal knots suture to unidirectional barbed suture during laparoscopic myomectomy. The mean total operation time and the mean suturing time were shorter in the barbed suture arm, but only the reduction of time of 
Table 3. Studies of laparoscopic myomectomy with or without barbed suture: peroperative complications data

\begin{tabular}{lll}
\hline Authors and year of publication & Complications barbed group, $n$ & Complications control group, $n$ \\
\hline Alessandri et al. [19], 2010 & 0 & 0 \\
\hline Einarsson et al. [20], 2011 & $\begin{array}{l}1 \text { blood transfusion, } \\
1 \text { ileus, } \\
2 \text { incision site infection, } \\
4 \text { urinary tract infection }\end{array}$ & $\begin{array}{l}1 \text { intraoperative complication, } \\
2 \text { urinary tract infection }\end{array}$ \\
\hline Angioli et al. [6], 2012 & $\begin{array}{ll}1 \text { fever, } \\
1 \text { urinary infection }\end{array}$ & 1 fever \\
\hline Ardovino et al. [15], 2013 & 0 & $\begin{array}{l}0 * \\
0^{\circ}\end{array}$ \\
\hline Song et al. [30], 2014 & 0 & 0 \\
\hline Aoki et al. [29], 2014 & 0 & 0 \\
\hline Giampaolino et al. [31], 2015 & $\begin{array}{l}1 \text { fever, } \\
1 \text { urinary infection }\end{array}$ & 2 fever \\
\hline Tinelli et al. [32], 2016 & $\begin{array}{l}1 \text { blood trasfusion, } \\
5 \text { port site haematoma, } \\
13 \text { post opertaive haematoma, } \\
22 \text { fever }\end{array}$ & $\begin{array}{l}3 \text { blood trasfusion, } \\
9 \text { port site haematoma, } \\
22 \text { post operative haematoma }\end{array}$ \\
\hline
\end{tabular}

\footnotetext{
* Extracorporal knots.

$\circ$ intracorporal knots.

\# The authors reported an haematoma in post-operative time without specifing in which group of patient it was occurred.
}

uterine wall repair was statistically significant. Furthermore, $\mathrm{Hb}$ drop and the estimated blood loss were significantly lower in the barbed suture group, while no significant difference of length of hospitalization was proven.

Instead, Ardovino et al. [15] compared the bidirectional barbed suture with conventional sutures using extracorporal and intracorporal knots. The authors underlined that the time needed to repair the uterine wall defect was significantly shorter in the barbed suture group than that in the conventional suture arm. Also, the VAS of suturing difficulty was significantly lower in the barbed suture group than in the conventional suture group, irrespective of extracorporal or intracorporal knots. No significant difference was observed in the total operative time, though; also, the estimated blood loss and $\mathrm{Hb}$ drop were similar in the 3 arms. The authors confirmed that barbed sutures are safe and rapid for repairing the uterine breach after laparoscopic myomectomy.

According to a retrospective trial conducted by Aoki et al. [29], the mean total operative time was significantly shorter in the barbed suture arm than in the convention- al suture one. No significant differences were reported in relation to age, BMI, estimated blood loss/Hb drop, length of hospitalization, and weight of myoma(s).

Even Song et al. [30] compared the use of barbed unidirectional barbed filament to traditional filaments, after laparoscopic single-site myomectomy, and proved that barbed suture could significantly reduce the mean total operation time and the mean suturing time. The estimated blood loss and VAS of suturing difficulty were significantly lower in the barbed suture group. No significant difference was found in age, BMI, weight, size and number of myomas, and length of hospitalization between the 2 study groups.

Giampaolino et al. [31] performed a prospective randomized trial including laparoscopic myomectomies of single posterior intramural myoma, with a diameter of 4-7 cm, in order to compare bidirectional barbed suture to conventional suture with intracorporal knots. These authors showed that barbed sutures could significantly decrease the total operative time, blood loss, and suturing time also in the treatment of myomas of the uterine posterior wall. 
Tinelli et al. [32] in a multicenter retrospective study, with the largest number of patients, investigate clinical outcomes after laparoscopic myomectomy related to the use of traditional interrupted sutures or continuous barbed suture. This trial demonstrated that the use of barbed filaments is a valid opportunity in the treatment of symptomatic myoma during laparoscopic procedure, especially in case of 3 or more uterine myomas.

The fertility outcomes represent an important goal after laparoscopic myomectomy in young women. In fact, it is absolutely important to promote the integrity of the repair of uterine wall after myomectomy. The real purpose of barbed sutures in patients looking for pregnancy is not clear yet. As a matter of fact, there is not sufficient data regarding the impact of barbed filaments on uterine tissue and the long-term outcomes of suture of uterine breach through barbed knots.

In 2012, Sandberg et al. [33] concluded that the additional use of barbed suture does not modify the pregnancy outcome. They reported a rate of $58.85 \%$ of pregnancies in patients subjected to laparoscopic myomectomy in the previous year. At the time of analysis, $52 \%$ had a live birth, $36 \%$ had a miscarriage, and 3 were still pregnant at the time of analysis. On average, patients became pregnant at 9.64 months after surgical procedure. Authors also investigated modalities of delivery: 2 patients had a vaginal delivery, whereas 11 underwent a Caesarean section, at a mean gestational time of 38 weeks +6 days. There were no cases of uterine rupture or placenta previa. In conclusion, laparoscopic myomectomy should be considered safe.

Also, Racca et al. [34] in 2015, analyzed pregnancy and delivery outcomes after laparoscopic myomectomy was performed with the unidirectional barbed suture. On average, $55.7 \%$ of patients conceived spontaneously 5.7 months after surgery, while $18 \%$ conceived by assisted reproductive technologies. These authors reported 5 miscarriages and one voluntary interruption of pregnancy. Ten pregnancies were ongoing at the time of the study. Seventeen patients delivered by Caesarean section (13 because of previous myomectomy), and 12 patients had labor and vaginal delivery. Also, this paper did not report any case of uterine rupture or placenta previa.

Ardovino et al. [15] investigated pregnancy outcomes of barbed myomectomy versus traditional techniques. Thirteen patients from the barbed group and 26 patients among controls ( 11 women with intracorporal knots and 15 with extracorporal knots) became pregnant during the follow-up period after surgical procedures. While $48 \%$ of women conceived spontaneously, $36 \%$ resorted to assist-

The Use of Barbed Suture in Laparoscopic Myomectomy ed medical reproduction techniques. Forty deliveries (4 twin pregnancies) and 3 miscarriages were recorded. The rate of Caesarean section was $48.3 \%$.

It was not feasible to rule out a meta-analysis of pregnant outcomes, since included trials reported only data about pregnancies in patients treated with barbed filaments and not in control subjects.

\section{Discussion}

In 2008, Greenberg and Einarsson [21] were the first to describe the use of bidirectional barbed filament for suturing the uterine breach in a retrospective trial. In 2010, Einarsson et al. [35] declared that barbed suture could be safe and useful to repair the uterine wall defect after myomectomy. According to the prevailing times, several clinical trials and case reports have already been published on the use of barbed suture in laparoscopic myomectomy. Moreover, barbed materials represent a field of great interest because suture techniques used for laparoscopic myomectomy play a fundamental role in gynecologic and, particularly, in minimally invasive surgery. Indeed, through a significant reduction of operative times of vaginal vault closure after total laparoscopic hysterectomy, barbed suture leads to an improvement of patients' benefits and a considerable decrease of hospitalization costs $[36,37]$. In accordance to previous data of literature $[26,38]$, which underlined how barbed suture could reduce total operation time, the use of barbed filament decreased the time required to suture the uterine wall defects after myomectomy.

A notable benefit of barbed suture is the opportunity to maintain the tension of uterine tissue during the suture procedure. The presence of barbs on the filament causes an equal distribution of tensile strength along the suture line and tissue in an effective way. Also, the absence of knots reduces the damage of uterine tissue due to tears or lacerations that might occur in the area surrounding the knot. Indeed, the use of barbed suture allows the possibility to repair the uterine wall defect in shorter time. The time needed to suture the uterine wall defect is statistically and significantly lower in the barbed group than in the traditional sutures $(p<0.0001)$, with a significant reduction of surgical time in the laparoscopic myomectomy when the surgeons use barbed filaments $(p<0.0001)$ in opposition with the application of intracorporal or extracorporal traditional knots.

Moreover, our meta-analysis underlines that technical difficulty results significantly lower in the barbed suture 
in comparison with the control group $(p<0.0001)$. In agreement with Siedhoff et al. [22], we supposed that lower difficulty linked to barbed suture could be explained by characteristics of filaments and shorter learning curve.

Nevertheless, according to our analysis, weight, position, number, and size of myomas do not significantly influence operative and suturing time, as well as surgical difficulties of laparoscopic myomectomy.

During laparoscopic or laparotomic myomectomy, the most significant aspect of surgical procedure is the inevitable blood loss derived from the uterine lesion to enucleate the myoma. In fact, only the tension of suture and the velocity to repair the uterine wall defect can control the bleeding of the uterine tissue and prevent hematomas. The characteristics of barbed filaments allow a better control of hemostasis in the site of hysterotomy and intraoperative bleeding. In this meta-analysis, barbed sutures were found to be favorable in comparison with the control group also with regard to the total operative blood loss $(p=0.098)$ and the consequent hemoglobin drop $(p=0.183)$. As already shown by Tulandi and Einarsson [26], blood loss and suturing time are strongly related to the total number, diameter and size of myomas, use of vasoconstrictors or previous use of $\mathrm{GnRH}$ to limit uterine bleeding, type of uterine wall incision, and experience of surgeons. However, also the presence of adhesions due to previous surgery, uterine volume, different anatomy of genital tract, and/or comorbidities of patients might influence total operative time.

The reduction of uterine bleeding, consequent to a good hemostasis, shorter suturing time and total operative time, due to barbed filaments, and also the use of laparoscopic surgery, all have surely an important impact on the hospital stay. The reduction of time of patients' recovery represents an important outcome because of the following reasons: a shorter hospitalization positively influences the physical and emotional quality of life of patients and can also reduce the cost of hospital assistance. Hence, the application of barbed filaments during laparoscopic myomectomy has results that are found to be superior to those of traditional filament especially in terms of the time of recovery $(p=0.04)$.

Previous authors underlined that barbed materials are more expensive than conventional filaments [19]. In our opinion, the costs-benefits analysis would seem to report a net benefit of barbed sutures in terms of reduction of operative time and intraoperative blood loss, hence balancing the higher costs of materials [30]. Therefore, the reduction of time of patients' recovery and of hospital assistance can compensate the higher costs of barbed filaments.
As regards perioperative complications, we noticed that not all authors reported the adverse events that occurred during the operative procedure or during the postsurgical period. The complications reported were fever, urinary infection, blood transfusion, and hematomas. The most significant characteristics of adverse events and patients involved in each study are summarized in Table 3. In terms of perioperative complications, there was a significant difference between the 2 groups $(p=0.046)$. Probably the benefit of barbed sutures decreases the onset of adverse effects; that is because it can reduce the total operative time, with subsequent reduction of perioperative nosocomial infections and organic stressed events. The adequate tension of the suture line during tissue repairing and the good hemostasis avoid the risk of formation of hematoma and bleeding in the post-surgical time. However, previous reports highlighted that a relevant disadvantage of barbed filaments is the risk of bowel obstruction or intestinal volvulus. Indeed, if the filaments have not been cut near the tissue at the end of the suture, the remaining portion might adhere to the intestinal wall, leading to an impairment of bowel function, vascular lesion, and intestinal dilatation. Cutting barbed filament short enough should reduce these risks [26, 31, 39-41]. Nevertheless, Einarsson et al. [42] showed that the risk of postoperative abdominal adhesions is similar to that which prevails after the use of conventional and barbed sutures. In this meta-analysis, no bowel involvement was reported.

The role of pregnancy on uterine myomas is not clear yet. The fibroids in pregnant women require particular attention in order to preserve pregnancy and fetal wellness. In fact, the fibroids have a significant dimensional increase during the first trimester. Nevertheless, the modification of myomas during the second and third trimesters is not definite: probably uterine myomas let up their growth in mid pregnancy, and their size decreases during the last period of pregnancy. Also, during the pregnancy, the total modification of fibroids does not appear to be understandable [43]. During pregnancy, the surgical treatment of myomas is performed in selected cases: torsion of pedunculated fibroid, necrosis of myoma with consequent peritoneal inflammation; in fact, the risk of myomectomy and surgical complications, also during caesarean section, overcome the benefits of conservative approach. Usually the treatment of fibroids in pregnant women, if it is necessary, is based on medical therapy [44]. However, myomectomy has a significant role in women desiring future pregnancy because the surgical removal of fibroids can increase the fertility rate, restore the uterine
Gardella/Dominoni/Iacobone/ De Silvestri/Tinelli/Bogliolo/Spinillo 
anatomical structure, reduce the local tissue inflammation reaction, and promote the adequate uterine blood provisions [45].

Limited data of literature about the impact of barbed filaments on pregnancy and delivery outcomes do not allow an exhaustive analysis and a definitive opinion on the safety of this technique and risks of obstetric adverse events (i.e., uterine rupture and placental complications). Furthermore, it is not possible to convey about the delivery modalities; in fact, a long-term follow-up is mandatory to identify the timing of delivery and the possibility of labor and vaginal delivery versus the Caesarean section.

In animal models, the use of barbed suture leads to the same healing of the uterine breach as with the use of traditional filaments [46]. Indeed, the use of barbed sutures or traditional filaments determinates the same quality of connective tissue, muscle cells, smooth muscle cell actin expression, and the similar proliferation of cells in the ovine uterine wall. Nowadays, clinical trials about the process of healing of the uterine breach through standard or barbed suture are not available. It will be necessary to investigate the real impact of the application of these techniques in humans, especially in relation to the risk of uterine rupture during pregnancy.

Several limitations might be found in our analysis. First of all, we compared results from non-homogeneous trials, such as prospective, randomized, and retrospective studies. Moreover, data were derived from authors that employed both bidirectional and unidirectional barbed suture, intracorporal and extracorporal knots, and different surgical techniques, with no differentiation during the elaboration of results. Second, the data regarded pa- tients with different size, number, and position of myomas. As a matter of fact, the trials included in our metaanalysis are not homogeneous especially in relation to the characteristics of myoma. It is widely known that different features of myomas can significantly influence surgical procedure, suturing time, bleeding, total operative time, and also perioperative complications. Another bias could derive from the exclusion of letters, preliminary trials, editorial comments, and papers regarding robotic-assisted surgery. These papers were not included in our literature review, since they could not reveal information on an exhaustive analysis of clinical outcomes, potential roles and adverse events of barbed versus conventional sutures.

In conclusion, the use of barbed suture significantly facilitates laparoscopic myomectomy. Effectively, this filament reduces the total operative time and the estimated blood loss/Hb drop. These observations are justified by the fact that the suture of the uterine wall defects can be performed by gynecologists, easily and quickly, even if they were younger or less experienced.

These relatively new materials allow a good control of the quality of laparoscopic myomectomy, in terms of safeness and reduction of intraoperative and/or postoperative complications, consecutive modalities of delivery (caesarean section vs vaginal delivery) and possible obstetrics complications.

\section{Disclosure Statement}

The authors declare that they have no conflicts of interest to disclose.

\section{References}

1 Marshall LM, Spiegelman D, Barbieri RL, Goldman MB, Manson JE, Colditz GA, et al: Variation in the incidence of uterine leiomyoma among premenopausal women by age and race. Obstet Gynecol 1997;90:967973.

-2 Sudik R, Hüsch K, Steller J, Daume E: Fertility and pregnancy outcome after myomectomy in sterility patients. Eur J Obstet Gynecol Reprod Biol 1996;65:209-214.

- 3 Brahma PK, Martel KM, Christman GM: Future directions in myoma research. Obstet Gynecol Clin North Am 2006;33:199-224.

-4 Cezar C, Becker S, di Spiezio Sardo A, et al: Laparoscopy or laparotomy as the way of entrance in myoma enucleation. Arch Gynecol Obstet 2017;296:709-720.
5 Vitale SG, Sapia F, Rapisarda AMC, Valenti G, et al: Hysteroscopic morcellation of submucous myomas: a systematic review. Biomed Res Int 2017;2017:6848250.

- 6 Angioli R, Plotti F, Montera R, Damiani P, Terranova C, Oronzi I, et al: A new type of absorbable barbed suture for use in laparoscopic myomectomy. Int J Gynaecol Obstet 2012;117:220-223.

7 Alessandri F, Lijoi D, Mistrangelo E, Ferrero S, Ragni N: Randomized study of laparoscopic versus minilaparotomic myomectomy for uterine myomas. J Minim Invasive Gynecol 2006;13:92-97.

-8 Holzer A, Jirecek ST, Illievich UM, Huber J, Wenzl RJ: Laparoscopic versus open myomectomy: a double-blind study to evaluate postoperative pain. Anesth Analg 2006;102: 1480-1484.

-9 Jin C, Hu Y, Chen XC, Zheng FY, Lin F, Zhou $\mathrm{K}$, et al: Laparoscopic versus open myomectomy - a meta-analysis of randomized controlled trials. Eur J Obstet Gynecol Reprod Biol 2009;145:14-21.

10 Mais V, Ajossa S, Guerriero S, Mascia M, Solla E, Melis GB: Laparoscopic versus abdominal myomectomy: a prospective, randomized trial to evaluate benefits in early outcome. Am J Obstet Gynecol 1996;174:654-658.

11 Palomba S, Zupi E, Russo T, Falbo A, Marconi $\mathrm{D}$, Tolino A, et al: A multicenter randomized, controlled study comparing laparoscopic versus minilaparotomic myomectomy: shortterm outcomes. Fertil Steril 2007;88:942-951. 
-12 Song T, Cho J, Kim TJ, Kim IR, Hahm TS, Kim BG, et al: Cosmetic outcomes of laparoendoscopic single-site hysterectomy compared with multi-port surgery: randomized controlled trial. J Minim Invasive Gynecol 2013;20:460-467.

13 Giampaolino P, Morra I, Tommaselli GA, et al: Post-operative ovarian adhesion formation after ovarian drilling: a randomized study comparing conventional laparoscopy and transvaginal hydrolaparoscopy. Arch Gynecol Obstet 2016;294:791-796.

14 Giampaolino P, Morra I, Della Corte L, et al: Serum anti-Mullerian hormone levels after ovarian drilling for the second-line treatment of polycystic ovary syndrome: a pilot-randomized study comparing laparoscopy and transvaginal hydrolaparoscopy. Gynecol Endocrinol 2017;33:26-29.

-15 Ardovino M, Castaldi MA, Fraternali F, Ardovino I, Colacurci N, Signoriello G, et al: Bidirectional barbed suture in laparoscopic myomectomy: clinical features. J Laparoendosc Adv Surg Tech A 2013;23:1006-1010.

- 16 Jasonni VM, D’Anna R, Mancuso A, Caruso C, Corrado F, Leonardi I: Randomized double-blind study evaluating the efficacy on uterine fibroids shrinkage and on intra-operative blood loss of different length of leuprolide acetate depot treatment before myomectomy. Acta Obstet Gynecol Scand 2001;80: 956-958.

-17 Alborzi S, Ghannadan E, Alborzi S, Alborzi M: A comparison of combined laparoscopic uterine artery ligation and myomectomy versus laparoscopic myomectomy in treatment of symptomatic myoma. Fertil Steril 2009;92: $742-747$.

$\longrightarrow 18$ Frederick J, Fletcher H, Simeon D, Mullings A, Hardie M: Intramyometrial vasopressin as a haemostatic agent during myomectomy. $\mathrm{Br}$ J Obstet Gynaecol 1994;101:435-437.

-19 Alessandri F, Remorgida V, Venturini PL, Ferrero S: Unidirectional barbed suture versus continuos suture with intracorporal knots in laparoscopic myomectomy: a randomized study. J Minim Invasive Gynecol 2010;17: 725-729.

20 Einarsson JI, Chavan NR, Suzuki Y, Jonsdottir G, Vellinga TT, et al: Use of bidirectional barbed suture in laparoscopic myomectomy: evaluation of perioperative outcomes, safety, and efficacy. J Minim Invasive Gynecol 2011; 18:92-95.

21 Greenberg JA, Einarsson JI: The use of bidirectional barbed suture in laparoscopic myomectomy and total laparoscopic hysterectomy. J Minim Invasive Gynecol 2008; 15:621623.

22 Siedhoff MT, Yunker AC, Steege JF: Decreased incidence of vaginal cuff dehiscence after laparoscopic closure with bidirectional barbed suture. J Minim Invasive Gynecol 2011;18:218-223.

23 Demyttenaere SV, Nau P, Henn M, Beck C, Zaruby J, Primavera $\mathrm{M}$, et al: Barbed suture for gastrointestinal closure: a randomized control trial. Surg Innov 2009;16:237-242.

24 Greenberg JA: The use of barbed sutures in obstetrics and gynecology. Rev Obstet Gynecol 2010;3:82-91.

25 Greenberg JA, Goldman RH: Barbed suture: a review of the technology and clinical uses in obstetrics and gynecology. Rev Obstet Gynecol 2013;6:107-115.

26 Tulandi T, Einarsson JI: The use of barbed suture for laparoscopic hysterectomy and myomectomy: a systematic review and meta-analysis. J Minim Invasive Gynecol 2014;21:210216.

27 Manoucheri E, Einarsson JI: The use of barbed suture in hysterectomy and myomectomy. Surg Technol Int 2013;23:133-136.

28 Vessilou MC, Feldman LS, Andrew CG, Andrew CG, Bergman S, Leffondré K, et al: A global assessment too evaluaion of intraoperatie laparoscopic skills. Am J Surg 2005; 190: 107-113.

29 Aoki Y, Kikuchi I, Kumakiri J,Kitade M, Shinjo A, Ozaki R, et al: Long unidirectional barbed suturing technique with extracorporeal traction in laparoscopic myomectomy. BMC Surg 2014;27;14:84.

30 Song T, Kim TJ, Kim WY, Lee SH: Comparison of barbed suture versus traditional suture in laparoendoscopic single-site myomectomy. Eur J Obstet Gynecol Reprod Biol 2015; 185:99-102.

-31 Giampaolino P, De Rosa N, Tommaselli GA, Santangelo F, Nappi C, Sansone A, et al: Comparison of bidirectional barbed suture Stratafix and conventional suture with intracorporeal knots in laparoscopic myomectomy by office transvaginal hydrolaparoscopic followup: a preliminary report. Eur J Obstet Gynecol Reprod Biol 2015;195:146-150.

32 Tinelli R, Litta P, Angioni S, Bettocchi S, Fusco A, Leo L, et al: A multicenter study comparing surgical outcomes and ultrasonographic evaluation of scarring after laparoscopic myomectomy with conventional versus barbed sutures. Int J Gynaecol Obstet 2016;134:18-21.

33 Sandberg EM, Cohen SL, Hill-Lydecker CI, Vree FE, Einarsson JI: Pregnancy outcomes after laparoscopic myomectomy with barbed suture. J Minim Invasive Gynecol 2012; 19(suppl):S48.

34 Racca A, Alessandri F, Leone Roberti Maggiore U, Fausta S, Venturini PL, Ferrero S : Unidirectional knotless barbed suture for laparoscopic myomectomy: fertility, pregnancy and delivery outcomes. J Minim Invasive Gynecol 2015;22:S233.

- 35 Einarsson JI, Vellinga TT, Twijnstra AR, Chavan NR, Suzuki Y, Greenberg JA: Bidirectional barbed suture: an evaluation of safety and clinical outcomes. JSLS 2010;14:381285.

36 Bogliolo S, Musacchi V, Dominoni M, Cassani C, Gaggero CR, De Silvestri A, et al: Barbed suture in minimally invasive hysterectomy: a systematic review and meta-analysis. Arch Gynecol Obstet 2015;292:489-497

37 Bogliolo S, Nadalini C, Iacobone AD, Musacchi V, Carus AP: Vaginal cuff closure with absorbable bidirectional barbed suture during total laparoscopic hysterectomy. Eur J Obstet Gynecol Reprod Biol 2013;170:219221.

38 Iavazzo C, Mamais I, Gkegkes ID: The role of knotless barbed suture in gynecologic surgery: systematic review and meta-analysis. Surg Innov 2015;22:528-539.

39 Kindinger LM, Setchell TE, Miskry T: Bowel obstruction due to entanglement with unidirectional barbed suture following laparoscopic myomectomy. Gynecol Surg 2012;9:357358

40 Burchett MA, Mattar SG, McKenna DT: Iatrogenic intestinal and mesenteric injuries with small bowel volvulus following use of barbed suture during laparoscopic myomectomy. J Laparoendosc Adv Surg Tech A 2013; 23:632-634.

41 Rombaut S, Baulies S, Cusidó M, Barri-Soldevila P, Rodriguez, I Úbeda A: Quill barbed suturerelated complication. Gynecol Surg 2012;9:359-361.

42 Einarsson JI, Grazul-Bilska AT, Vonnahme KA: Barbed vs standard suture: randomized singleblinded comparison of adhesion formation and ease of use in an animal model. J Minim Invasive Gynecol 2011;18:716-719.

43 Vitagliano A, Noventa M, Di Spiezio Sardo A, et al: Uterine fibroid size modifications during pregnancy and puerperium: evidence from the first systematic review of literature. Arch Gynecol Obstet 2018;297:823-835.

44 Vitale SG, Tropea A, Rossetti D, et al: Management of uterine leiomyomas in pregnancy: review of literature. Updates Surg 2013;65: 179-182.

45 Vitale SG, Padula F, Gulino FA: Management of uterine fibroids in pregnancy: recent trends. Curr Opin Obstet Gynecol 2015;27: 432-437.

46 Einarsson JI, Vonnahme KA, Sandberg EM, Grazul-Bilska AT: Barbed compared with standard suture: effects on cellular composition and proliferation of the healing wound in the ovine uterus. Acta Obstet Gynecol Scand 2012;91:613-619. 